\title{
On the role of the planetary boundary layer depth in the climate system
}

\author{
I. Esau ${ }^{1,2}$ and S. Zilitinkevich ${ }^{1,3,4}$ \\ ${ }^{1}$ G.C. Rieber Climate Institute of the Nansen Environmental and Remote Sensing Center, \\ Thormohlensgt. 47, 5006, Bergen, Norway \\ ${ }^{2}$ Bjerknes Centre for Climate Research, Bergen, Norway \\ ${ }^{3}$ Division of Meteorological Research, Finnish Meteorological Institute, Helsinki, Finland \\ ${ }^{4}$ Division of Atmospheric Sciences and Geophysics, Department of Physics, University of Helsinki, Finland
}

Received: 29 January 2010 - Revised: 13 April 2010 - Accepted: 26 April 2010 - Published: 17 May 2010

\begin{abstract}
The planetary boundary layer (PBL) is a part of the Earth's atmosphere where turbulent fluxes dominate vertical mixing and constitute an important part of the energy balance. The PBL depth, $h$, is recognized as an important parameter, which controls some features of the Earth's climate and the atmospheric chemical composition. It is also known that $h$ varies by two orders of magnitude on diurnal and seasonal time scales. This brief note highlights effects of this variability on the atmospheric near-surface climate and chemical composition. We interpret heat capacity parameter of a Budyko-type energy balance model in terms of quasi-equilibrium $h$. The analysis shows that it is the shallowest, stably-stratified PBL with the smallest $h$ that should be of particular concern for climate modelling. The reciprocal dependence between the PBL depth and temperature (concentrations) is discussed. In particular, the analysis suggests that the climate characteristics during stably stratified PBL episodes should be significantly more sensitive to perturbations of the Earth's energy balance as well as emission rates. On this platform, $h$ from ERA-40 reanalysis data, the CHAMP satellite product and the DATABASE64 data were compared. DATABASE64 was used to assess the Troen-Mahrt method to determine $h$ through available meteorological profile observations. As it has been found before, the shallow PBL requires better parameterization and better retrieval algorithms. The study demonstrated that ERA-40 and CHAMP data are biased toward deeper $h$ in the shallow polar PBL. This, coupled with the scarcity of in-situ observations might mislead the attribution of the origins of the Arctic climate change mechanisms.
\end{abstract}

\section{Introduction}

The lowermost atmospheric layer where the vertical turbulent exchange is significant is known as the planetary boundary layer (PBL). The importance of the PBL for the Earth's climate system has been recognized since pioneering work of Manabe and Strickler (1964). However, there are just a few studies (e.g. Knight et al., 2007), which excurse beyond the current narrow focus on PBL parameterizations in climate models. Using a classification and regression tree approach, Knight et al. (2007) demonstrated with 57067 climate model HadAM3 runs that $80 \%$ of variation in climate sensitivity to $2 \times \mathrm{CO}_{2}$ is associated with variation of a small subset of parameters mostly related to the convection pro-

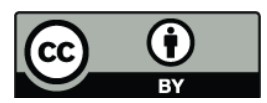

Correspondence to: I. Esau

(igore@nersc.no) cesses. The most influential parameter (32\% of the total variability) appeared to be the entrainment rate, $A$, which defines the top down (counter-gradient) turbulent flux at the PBL upper boundary. The PBL mass budget leads to the direct proportionality between the PBL depth, $h$, and the entrainment rate (Medeiros et al., 2005). Knight et al. (2007) reported the highest climate sensitivity for the lowest $A$, found in the shallowest PBL. The reciprocal relationship between the climate sensitivity and the PBL depth suggests larger climate variability in stably stratified boundary layers (Esau, 2008; Zilitinkevich and Esau, 2010), where $h$ is small, typically less than $200 \mathrm{~m}$ in nocturnal PBL as to be compared to its daytime counterpart with $h>1000 \mathrm{~m}$ (e.g. Medeiros et al., 2005). So far, very little attention has been paid to the stably stratified PBL. Its parameterizations are unreliable (Beare et al., 2006; Cuxart et al., 2006) and often overestimate $h$ in simulations (Mauritsen et al., 2007). Corresponding damping of model sensitivity has been demonstrated at high-latitudes (Beesly 
et al., 2000; Byrkjedal et al., 2008). Nevertheless, at present, the primary attention of climatologists is still focused on the daytime PBL (Stone and Weaver, 2003; Walters et al., 2007). This study consists of two distinct sections. Section 2 looks at the bulk PBL effect and the PBL depth in a simple energy balance model. Section 3 addresses challenges of PBL depth diagnostics.

\section{Bulk planetary boundary layer effect on the climate system}

In spite of remarkable progress in climate modelling and observation systems, a simple zero-dimensional energy balance climate model remains instrumental in understanding of the climate processes and mechanisms (North et al., 1981). In particular, utility of these models is in suggesting directions for statistical analysis of more comprehensive data from observations and modelling in order to separate certain physical effects. Following (Budyko, 1969; North et al., 1981; Esau, 2008; Zilitinkevich and Esau, 2010), we consider a Budykotype energy balance model. The model reads

$C \frac{d T}{d t} \propto F_{T}-F_{T 0}$,

where $T$ is temperature, $F_{T}$ is the divergence of the temperature flux, and $C$ is the heat capacity of the system. On the Earth, positive and negative $F_{T}$ alternate on different time scales, primarily on diurnal and annual time scales, to make climate, i.e. the state where the averaged over many years $d T / d t \rightarrow 0$. Addition of the averaged equilibrium flux, $F_{T 0}$, for which $d T / d t \rightarrow 0$, allows studies of a transient climate change in deviations from a unknown equilibrium state. Traditionally, the attention of the climate research community is focused on investigation of perturbations caused by $F_{T 0}$ response on the shift of the radiation heat balance. North et al. (1981) review and the very recent Zaliapin and Ghil (2010) insightful analysis are just two examples of such a work. Contrary, the system heat capacity, $C$, has not received much attention. In a system where the role of turbulent mixing is significant, one can simplify as $C \propto h$. Here, we assumed that complexity of the turbulent mixing processes could be parameterized through a single integral parameter, namely, the PBL depth $h$. The interested reader can find reservations and restrictions of this approach as well as supporting data in Esau (2008) and Zilitinkevich and Esau (2010).

As it follows from the traditional climatological convention, $T$ should be understood as the mean (global and seasonal averaged) surface air temperature. This convention immediately raises problems of aggregation of the system heat capacity and the temperature fluxes. We will not excurse into those problems making a silent assumption that both quantities are aggregated properly. Moreover, we assume that our model in Eq. (1) does not have sub-scale temporal variability. The temperature change represents the direct transition of the system from the unperturbed to a perturbed state. One should remember that these energy balance models are not to quantify behavior of the real Earth's climate system, which is incomparably more complex, but to suggest approaches to data analysis.

Thus, with respect to the PBL effects, the model in Eq. (1) reads

$\frac{d T}{d t}=c_{T 0} \frac{F_{T}-F_{T 0}}{h}$.

Here, $c_{T 0}$ is a non-dimensional proportionality coefficient, $h$ is dynamic quantity ultimately depending on $F_{T 0}$ and therefore on $T$, which suggest a possible non-linear PBL feedback in this kind of models. Esau (2008) and Zilitinkevich and Esau (2010) provided more materials to elaborate on the PBL feedback. We, however, will focus only on the bulk effects related to large variability of $h$.

Equation (2) immediately reveals several falsifiable propositions: (a) the temperature response to a given flux perturbation should have larger magnitude in the shallower PBL where $h$ is small; (b) the temperature variability should be larger in the shallow PBL; and (c) the temperature change is faster in the shallow PBL. One should observe that the temperature has probably stronger links with radiation processes and atmospheric large-scale dynamics hidden in $F_{T 0}$ than with the vertical turbulent mixing hidden in $h$. Manabe and Strikler (1964) and following works with the radiationconvective models (Ramanathan and Coakley, 1978; Randall et al., 1996) have demonstrated that this is not the case for the global scale climate as such. However, it could be the case for small perturbations (e.g. due to doubling of $\mathrm{CO} 2$ concentration) and on local scales. Moreover, only the local scale data will be available for direct analysis of the PBL effects as the nature of aggregation process remains unspecified.

One of possible ways to circumvent, at least partially, those difficulties is to recast Eq. (2) in terms of a scalar concentration, $Q$. It reads

$\frac{d Q}{d t}=c_{Q 0} \frac{F_{Q}-F_{Q 0}}{h}$,

where $c_{Q 0} \neq c_{T 0}$ is a non-dimensional proportionality coefficient, $Q$ is the scalar concentration and $F_{Q 0}$ is the divergence of the scalar flux. If $Q$ represents a long-lived scalar with its emission source predominantly within the PBL then, over sufficiently large homogeneous area, $F_{Q 0}$ is mostly controlled by the turbulent mixing. In this case, the bulk PBL effect could be separated in almost pure, laboratory conditions.

This study is not aimed to publish comprehensive analysis of the PBL effects in the Earth's system data. Therefore, it will be only demonstrated that the existing data are consistent with the proposed effects (a)-(c) both on global and local scales. First, we envisage the way to approach the temperature analysis. The PBL depth is the key parameter in Eq. (2). The variability of the PBL depth could be simplified as: $h_{C} \sim \mathrm{O}\left(10^{3} \mathrm{~m}\right)$ with the typical value $\overline{h_{C}}=1500 \mathrm{~m}$, 

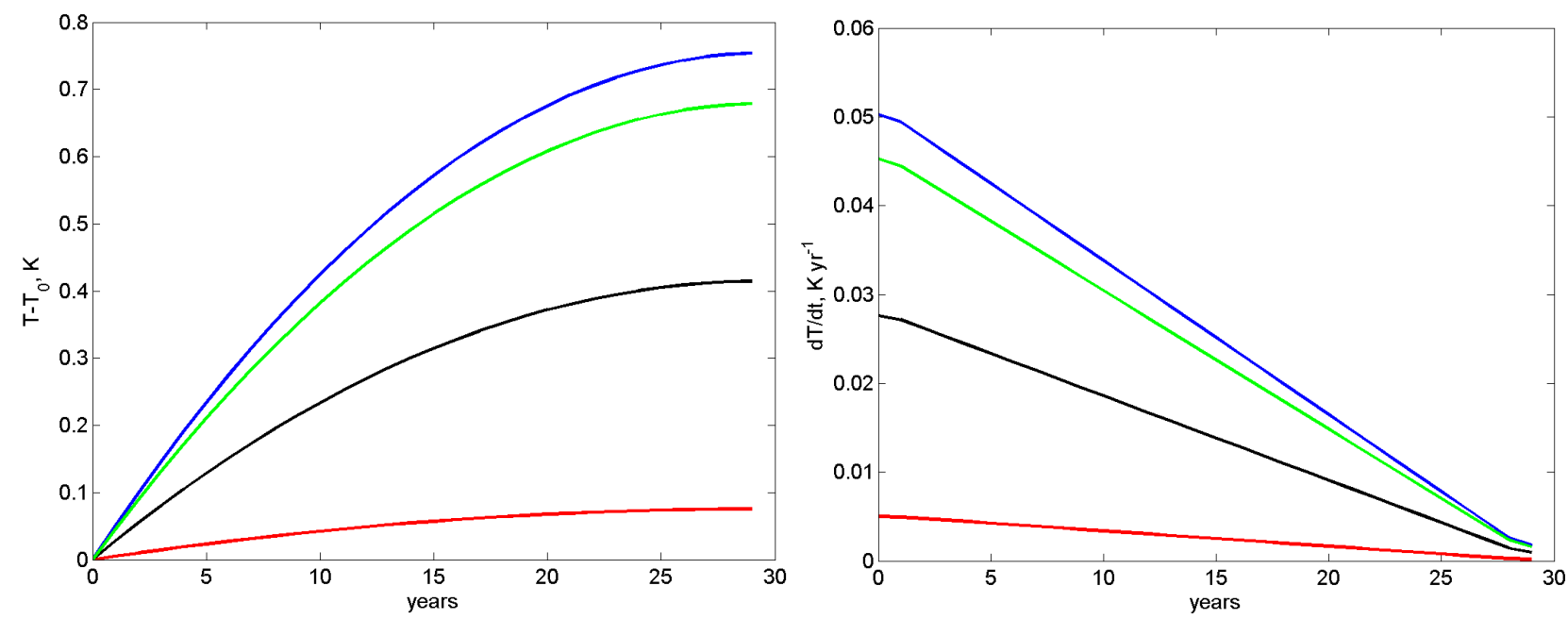

Figure 1. Response (a) of the temperature after Eq. (1) and its change rate (b) on an instant perturbation of the temperature flux by the observed green-house gas forcing. The constant $c_{T 0}=1000$ has been chosen in the way to bring the mean temperature change close to the observed one over the last 30 years. The black line denotes the mean temperature $0.5\left(T_{\max }+T_{\min }\right)$; the blue line - the minimum temperature $T_{\min }$; the red line - the maximum temperature $T_{\max }$; the green line - the diurnal temperature range change $\left(T_{\min }-T_{\max }\right)$. The initial state has been subtracted for all quantities.

- a characteristic depth of the convective, mostly daytime $\mathrm{PBL}$; and $h_{S} \sim \mathrm{O}\left(10^{2} \mathrm{~m}\right)$ with the typical value $\overline{h_{S}}=150 \mathrm{~m}$, - a characteristic depth of the stably-stratified, mostly nighttime PBL. These two distinct types of the PBL could be segregated in data and the corresponding temperature changes could be calculated. Since, in the most of cases, the turbulent convection is a dynamical reaction of the atmosphere on the positive surface heat balance, the convective PBL should be characterized by temperature maximums. Contrary, the stably stratified PBL forms during periods with the negative heat balance. Hence it should be characterized by temperature minimums.

Several studies of the diurnal temperature maximum, $T_{\max }$, and minimum, $T_{\min }$, have been published to date (e.g. Hansen et al., 1995; Braganza et al., 2004; Vose et al., 2005). We consider here how the energy balance model in Eq. (2) will react on the gradual change of the forcing. The globally averaged green-house gas temperature forcing is $\Delta F_{T 0} \sim$ $2.6 \times 10^{-5} \mathrm{~K} \mathrm{~m} \mathrm{~s}^{-1} \mathrm{yr}^{-1}$ for 30 year between 1979 and 2008 (Annual Greenhouse Gas Index, NOAA Earth System Research Laboratory, Global Monitoring Division, http://iasoa. org/iasoa/index.php). We impose a new climate equilibrium with $F_{T 1}=F_{T 0}+30 \Delta F_{T 0}$ and integrate Eq. (2) to find the minimum and maximum temperature adjustment in the deep and shallow PBLs correspondingly. To do this, we plot in Fig. 1 the following illustrative solution

$T(t)-T(t=0)=c_{T 0} \frac{F_{T 1}-F_{T}(t)}{h}=c_{T 0} \frac{30 \Delta F_{T 0}-t \Delta F_{T 0}}{h}$.

As one can see, $\Delta T_{\max }$ increases slower and changes on much smaller value than $\Delta T_{\min }$ does. Therefore, the diurnal temperature range (DTR) reduces. Its reduction accumulates with time but the strongest reduction would be seen during periods of the strongest temperature flux forcing. Interesting that in warmer climate, it is rather unlikely to observe decrease of $\overline{h_{C}}$ or $\overline{h_{S}}$ since the latter is already too small to show significant relative variations and the former cannot decrease in response on increasing temperature flux. There will be probably less cases and shorter periods with $\overline{h_{S}}$, which does not help to increase DTR either. Thus, the differential extreme temperature change and the decrease of the DTR over long time should be considered as the robust signature of the climate warming caused by the radiation balance shift due to the change of the atmospheric composition. In simple words, the difference in the PBL depth during day and night time leads to greatly suppressed response in the daytime temperature relative to that in the night time.

Rudimentary and idealized estimations given above are however in surprisingly good agreement with available analysis of observations. Braganza et al. (2004) give the rates $\Delta T_{\max }=0.1 \mathrm{~K} \mathrm{dec}^{-1}$ and $\Delta T_{\min }=0.2 \mathrm{~K} \mathrm{dec}^{-1}$ for the 50 years' period between 1950 and 2000 , which leads to $\left(T-T_{0}\right)_{\max }=0.3 \mathrm{~K}$ and $\left(T-T_{0}\right)_{\min }=0.6 \mathrm{~K}$ over 30 years. However, Vose et al. (2005) and Hansen et al. (1995) found $\Delta T_{\max } \approx \Delta T_{\min } \approx 0.29 \mathrm{~K} \mathrm{dec}^{-1}$ for a shorter period of time. The energy balance model suggests that there should be continues decrease of the DTR, albeit probably at slower rate, until new equilibrium has been reached. One should remind however that $70 \%$ of the Earth's surface is covered by ocean where the amplitude of the diurnal cycle in the PBL is significantly reduced. 


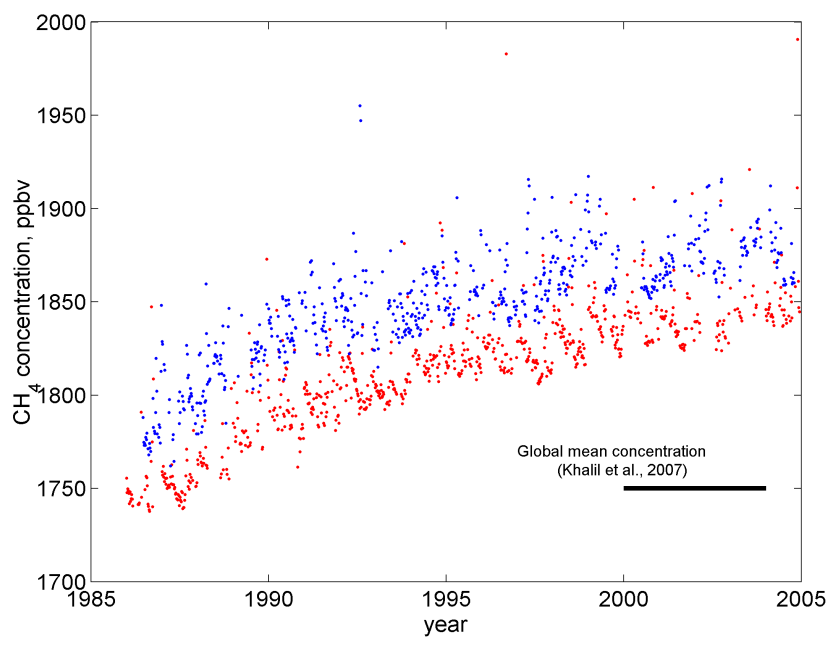

Figure 2. Daily averaged methane concentration obtained from NOAA/CMDL data at Barrow: red dots - summertime (June-July) data; blue dots - wintertime (December-January) data.

The differential temperature change is of primarily interest for climate research. The interest in the concentration variability comes from many applications dealing also with shorter than decadal time scales. The bulk PBL effect on seasonal concentration of methane, $\mathrm{CH}_{4}$, is shown in Fig. 2. This Figure reveals very powerful bulk PBL effect. The near surface concentration of $\mathrm{CH}_{4}$ is systematically higher (by about 100 parts per billion in volume, ppbv) than the concentration of $\mathrm{CH}_{4}$ in the free atmosphere (Khalil et al., 2007). This is expected as the primary $\mathrm{CH}_{4}$ emission is originated from the surface (Walter et al., 2006). Since about 1998-1999, the average near-surface seasonal concentrations do not increase which is consistent with the global free atmosphere records. Thus, one can conclude that the local emission of $\mathrm{CH}_{4}$ remains nearly constant over the period of observations or it varies as a proportion of the free atmosphere methane concentration, which is highly unlikely. Hence, both winter and summertime $\mathrm{CH}_{4}$ concentrations are determined by the local emission of the gas. Mastepanov et al. (2008) found significant methane release on the onset of the freezing season, which is a border between somewhat significant methane emission during the short polar summer $(90$ days or so) and much lower emission during the long polar winter ( 270 days). Despite lower emission rate in wintertime, the $\mathrm{CH}_{4}$ concentration remains significantly higher. It exhibits large ( $\sim 50 \mathrm{ppbv})$ variations on a week scale, which suggest that the individual release events could be mixed up into the free atmosphere during a week or so. At the same time, $\mathrm{CH}_{4}$ concentration always remains higher than that in summertime. These facts can be explained with Eq. (3). Both larger $\mathrm{CH}_{4}$ concentration and larger variability are understood as the effect of significant reduction of the PBL depth in response on the negative radiation balance and corresponding increase of the atmospheric stability. The convective mo- tions are damped that both confines $\mathrm{CH}_{4}$ in the shallow layer of $\overline{h_{S}} \sim 100 \mathrm{~m}$ and prevents its exchange with the free atmosphere due to build up of a strong radiation temperature inversion. ERA-40 (Uppala et al., 2005) data (a data selection within $2.5^{\circ}$ by $2.5^{\circ}$ rectangle centred at Barrow) revealed that $\overline{h_{C}}-\overline{h_{S}}$ is $\sim 300 \mathrm{~m}$. These data allow for rough estimation of the $\mathrm{CH}_{4}$ emission rate using only meteorological and concentration measurements. The mass of $\mathrm{CH}_{4}$ (per unit area), $M_{Q}$, emitted into the PBL should be equal to the mass of $\mathrm{CH}_{4}$ mixed into the free atmosphere during about 10 days. It can be calculated as

$M_{Q}=\frac{1}{2}\left(Q-Q_{0}\right) h$.

Now, we substitute for summertime $Q=1820 \mathrm{ppbv}, Q_{0}=$ $1760 \mathrm{ppbv}$ and $\overline{h_{C}}=400 \mathrm{~m}$. It gives the emission rate $M_{Q} \sim$ $1.2 \times 10^{-5} \mathrm{~kg} \mathrm{~m}^{-2} \mathrm{day}^{-1}$, which is fairly consistent with $\sim$ $1.0 \times 10^{-5} \mathrm{~kg} \mathrm{~m}^{-2}$ day $^{-1}$ obtained by Walter et al. (2007) in direct measurements. In wintertime, the numbers are as follows, $Q=1850 \mathrm{ppbv}, Q_{0}=1760 \mathrm{ppbv}$ and $\overline{h_{C}}=100 \mathrm{~m}$. It gives the emission rate $M_{Q} \sim 4.5 \times 10^{-7} \mathrm{~kg} \mathrm{~m}^{-2}$ day $^{-1}$, which is more than order of magnitude smaller than that in summertime. Thus, shallower PBL in wintertime could maintain the higher $\mathrm{CH}_{4}$ concentration in spite of the reduced emission.

\section{Boundary layer depth diagnosis using observa- tions, models and satellite products}

The PBL effects on climate are difficult to study because $h$ is not regularly observed quantity. It is diagnosed both in observations and simulations. Unfortunately, models reveal systematic overestimation and generally poor correlation between the simulated and observed $h$ in both convective and stably stratified PBL (Cuxart et al., 2006; Steeneveld et al., 2008). From Eq. (2) however follows that the bias in $h$ could lead to biased climatology. In order to estimate this bias, we used the ERA-40 data (Uppala et al., 2005) for the Barrow grid point as described above. Figure 3 shows the PBL depth estimated in the reanalysis and the satellite product CHAMP (von Engeln, 2005) as compared with the theoretical evaluation using corresponding ERA-40 external parameters (surface heat flux, atmospheric stability, and the wind speed) and the analytical relationship proposed and calibrated in Zilitinkevich et al. (2007). Figure 3 suggests a tendency of the ECMWF model (the model used for the ERA-40 reanalysis) to over-predict $h$ in stably stratified PBL revealed also in Mauritsen et al. (2007). The ERA-40 (blue) curve deviation in Fig. 3b is rather similar to the one found by Mauritsen et al. (2007) in direct intercomparison with the DATABASE64 cases. The over-prediction by the CHAMP retrieval algorithm could be possibly traced to that in ECMWF model, which is used to initialize the iteration retrieval algorithm (Marquardt et al., 2002). The good correspondence between CHAMP and ERA-40 data in tropical latitudes (von Engeln, 2005) is not confirmed for the high latitudes. Statistically, 

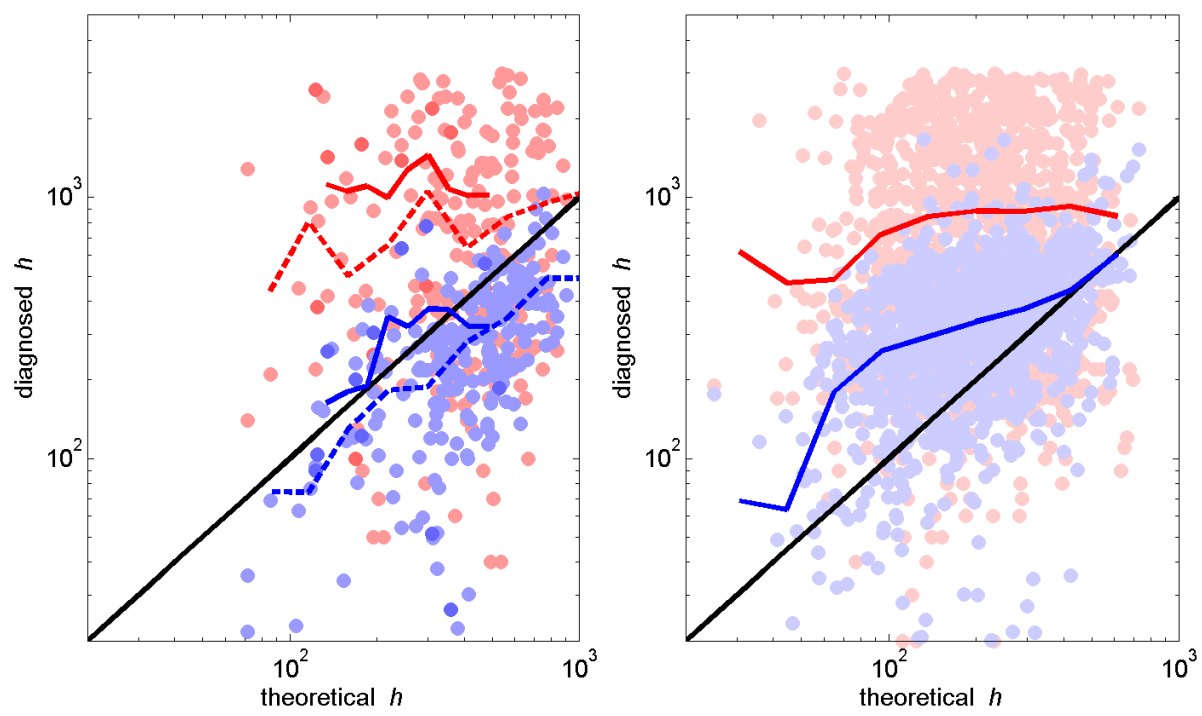

Figure 3. The daily averaged stably stratified quasi-steady state PBL depth, $h$. Days with convection and Monin-Obukhov length changes larger than $\Delta L=50 \mathrm{~m}$ per day are excluded. Following Zilitinkevich et al. (2007), data were separated in (a) nocturnal (solid curves; light dots) and conventionally neutral (dashed curves; dark dots) PBLs; (b) long-lived stably stratified PBL. Bluish dots and blue curves are the ERA-40 data. Reddish dots and red curves are the CHAMP data. The curves are the bin-averaged values of the corresponding data.

the ERA-40 data are in good agreement with the present understanding and turbulence-resolving simulation of the nocturnal and near-neutral PBLs. Parameterizations for those layers have been thoroughly calibrated for the purpose of the mid-latitude weather prediction with the model. At the same time, the long lived stably stratified PBL remains a challenge for the model.

The over-prediction of the shallow PBL and the underprediction of the deep PBL remain a challenging problem for other models as well. For instance Han et al. (2008) compared 5 PBL schemes in the Weather Research and Forecasting (WRF) model with observations in the Hong Kong area. Totally 145 samplings of $h$ were collected in 22 flights in March 2001. Both geographical and diurnal cycle patterns of $h$ showed only moderate correlation (correlation coefficients vary from 0.65 to 0.7$)$ to the observations. Typical nocturnal biases were found to be of $+300 \mathrm{~m}$ or about $100 \%$ of the observed $h$ values. Typical daytime biases were found to be $-300 \mathrm{~m}$ or about $30 \%$ of the observed $h$ values.

The diagnosis of the PBL depth in simulations (including ERA-40 reanalysis) and observations is usually based on the bulk Richardson number method by Troen and Mahrt (1986), which defines

$h: \quad R i(z)=R i_{c r}, \quad$ where $\quad R i=\frac{g}{\theta_{0}} \frac{\theta_{h}-\theta_{s}}{u_{h}^{2}} z$,

$\theta_{s}$ is the surface potential temperature; $\theta_{h}$ is the potential temperature at $h ; u_{h}$ is the wind speed at $h ; g / \theta_{0}=0.03 \mathrm{~m} \mathrm{~s}^{-2} \mathrm{~K}^{-1}$ is the buoyancy parameter; and $z$ is the height above surface. The method could be sensitive to a calibration of the critical value $R i_{\mathrm{cr}}$. In meteorological practice, $R i_{\mathrm{cr}}$ are taken in the range from 0.15 to 1.0 with often quoted values of 0.25 and 0.5 (Serafin and Zardi, 2005; Jeričević and Grisogono, 2006). We investigated the variability of $h$ as function of $R i_{\mathrm{cr}}$ in the stably stratified PBL collected in the large-eddy simulation database (The DATABASE64 could be downloaded from ftp://ftp.nersc.no/igor/NEW\%20DATABASE64/; Esau and Zilitinkevich, 2006). Since the large-eddy simulations resolve the PBL turbulence, the DATABASE64 gives the opportunity to determine $h$ by different methods and to compare the results of directly determined PBL depth, i.e. using turbulent flux profiles. Figure 4 shows the relative error, $\left(h_{\mathrm{TM}}-h_{\mathrm{LES}}\right) / h_{\mathrm{LES}}$, as a function of $R i_{\mathrm{cr}}$ for the conventionally neutral, nocturnal stable and long-lived stable PBL averaged over all corresponding runs in DATABASE64. Here, $h_{\mathrm{TM}}$ is the PBL depth defined by Eq. (6), $h_{\mathrm{LES}}$ is the PBL depth defined as a level where the vertical momentum flux is equal to $5 \%$ of its surface value. The minimum error is found on average for $R i_{\text {cr }}$ in the range 0.15 to 0.25 . Excluding the nocturnal PBL, we conclude that the Troen-Mahrt method is robust with optimal $R i_{\mathrm{cr}}=0.2$ and a negligible relative error. In the weakly stratified nocturnal PBL, $h$ is poorly defined. We also repeated these calculations with the Arctic Ocean Experiment data (Tjernstroem et al., 2005) that provide independent estimations of $h$ based on radiometer data and humidity, wind and temperature profiles. Those calculations provided very similar dependence to ones shown in Fig. 4. 


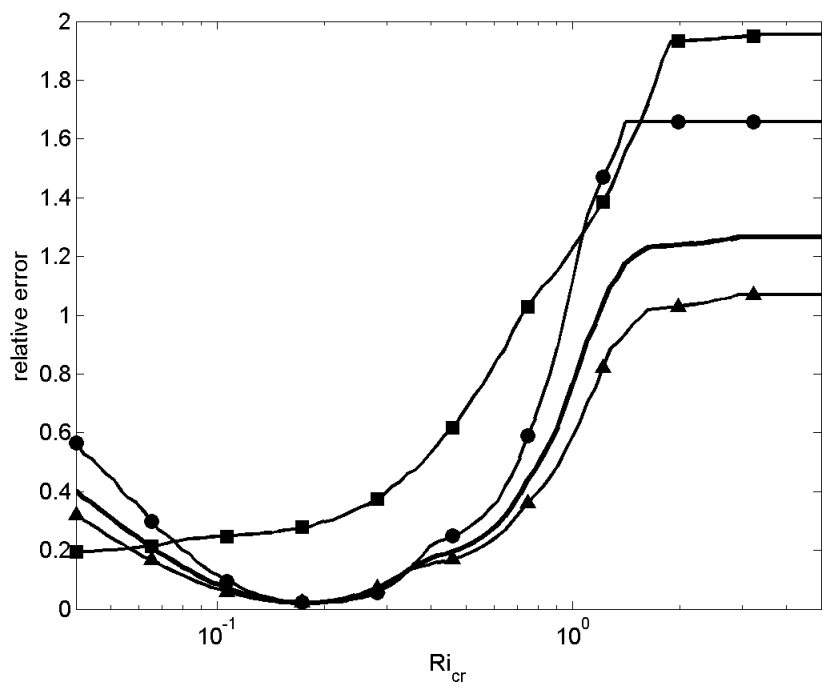

Figure 4. The relative error $\left(h_{\mathrm{TM}}-h_{\mathrm{LES}}\right) / h_{\mathrm{LES}}$, as functions of $R i_{\mathrm{cr}}$ for the nocturnal stable (squares), conventionally neutral (circles) and long-lived stable (triangles) PBL averaged over all corresponding runs in DATABASE64. The bold line without symbols is the mean line for the later two types of the PBL.

\section{Conclusions}

This work is motivated by the fact that the planetary boundary layer depth, $h$, is important for the Earth's climate. The first step to understand the bulk PBL effect on the Earth's climate is to consider the energy-balance model. The model leads to reciprocal dependence between the temperature/concentration changes and $h$. The dependence can be summarized as: (a) the temperature response to a given flux perturbation has larger magnitude in the shallower PBL where $h$ is small; (b) the temperature variability should be larger in the shallow PBL; and (c) the temperature change is faster in the shallow PBL. These points were illustrated using the temperature response on the green-house gas forcing since 1979 and the seasonal variability of the methane concentration at point Barrow (Alaska, USA). We found reasonable agreement in the observed trends and variability between the methane concentrations, temperature anomalies and the PBL depth with numbers found in literature. We demonstrated that the model parameterizations (ERA-40) and the satellite products (CHAMP) over-predict $h$ in shallow long-lived PBL typical in high-latitudes. This bias could and probably does cause climate model discrepancies in polar areas as those reported by Beesly et al. (2000). This bias and the scarce in situ observations in the region makes it difficult to ascribe the polar climate change pattern.
Acknowledgements. The research leading to these results has received funding from the EC FP7/2007-2011 programme under grant agreement no. 212520, the EC ERC programme grant PBL-PMES and the Norwegian Research Council grant PBL-FEEDBACK.

Edited by: A. M. Sempreviva

Reviewed by: three anonymous referees

\section{References}

Beare, R. J., MacVean, M. K., Holtslag, A. A. M., Cuxart, J., Esau, I., Golaz, J.-C., Jimenez, M. A., Khairoutdinov, M., Kosovic, B., Lewellen, D., Lund, T. S., Lundquist, J. K., McCabe, A., Moene, A. F., Noh, Y., Raasch, S., and Sullivan, P.: An intercomparison of large-eddy simulations of the stable boundary layer, Bound.Lay. Meteorol., 118(2), 2, 247-272, 2006.

Beesley, J. A., Bretherton, C. S., Jakob, C., Andreas, E. L., Intrieri, J. M., and Uttal, T. A.: A comparison of cloud and boundary layer variables in the ECMWF forecast model with observations at Surface Heat Budget of the Arctic Ocean (SHEBA) ice camp, J. Geophys. Res., 105(D10), 12337-12350, 2000.

Braganza, K., Karoly, D. J., and Arblaster, J.: Diurnal temperature range as an index of global climate change during the twentieth century, Geophys. Res. Lett., 31, L13217, doi:10.1029/2004GL019998, 2004.

Byrkjedal, Ø., Esau, I., and Kvamst, N.-G.: Sensitivity of simulated wintertime Arctic atmosphere to vertical resolution in the ARPEGE/IFS model, Clim. Dynam., 30(1-2), 687-701, doi:10.1007/s00382-007-0316-z, 2008.

Cuxart, J., Holtslag, A., Beare, R., Bazile, E., Beljaars, A., Cheng, A., Conangla, L., Ek, M., Freedman, F., Hamdi, R., Kerstein, A., Kitagawa, H., Lenderink, G., Lewellen, D., Mailhot, J., Mauritsen, T., Perov, V., Schayes, G., Steeneveld, G.-J., Svensson, G., Taylor, P., Weng, W., Wunsch, S., and Xu, K.-M.: SingleColumn Model Intercomparison for a Stably Stratified Atmospheric Boundary Layer, Bound.-Lay. Meteorol., 118(2), 273303, doi:10.1007/s10546-005-3780-1, 2006.

von Engeln, A., Teixeira, J., Wickert, J., and Buehler, S. A.: Using CHAMP radio occultation data to determine the top altitude of the Planetary Boundary Layer, Geophys. Res. Lett., 32(6), L06815, doi:10.1029/2004GL022168, 2005.

Esau, I: Formulation of the Planetary Boundary Layer Feedback in the Earth's Climate System, Computational Technologies, 13, special issue 3, 95-103, 2008.

Esau, I. N. and Zilitinkevich, S. S.: Universal dependences between turbulent and mean flow parameters instably and neutrally stratified Planetary Boundary Layers, Nonlin. Processes Geophys., 13, 135-144, doi:10.5194/npg-13-135-2006, 2006.

Han, Z., Ueda, H., and Ana, J.: Evaluation and intercomparison of meteorological predictions by five MM5-PBL parameterizations in combination with three land-surface models, Atmos. Environ., 42, 233-249, 2008.

Hansen, J., Sato, M., and Ruedy, R.: Long-term changes of the diurnal temperature cycle: implications about mechanisms of global climate change, Atmos. Res., 37, 175-209, 1995.

Jeričević, A. and Grisogono, B.: The critical bulk Richardson number in urban areas verification and application in a numerical weather prediction model, Tellus, 58A, 19-27, 2006. 
Khalil, M. A. K., Butenhoff, C. L., and Rasmussen, R. A.: Atmospheric methane: Trends and cycles of sources and sinks, Environ. Sci. Technol., 41(7), 2131-2137, doi:10.1021/es061791t, 2007.

Knight, C. G., Knight, S. H. E., Massey, N., Aina, T., Christensen, C., Frame, D. J., Kettleborough, J. A., Martin, A., Pascoe, S., Sanderson, B., Stainforth, D. A., and Allen, M. R.: Association of parameter, software, and hardware variation with largescale behaviour across 57,000 climate models, PNAS, 104(30), 12259-12264, 2007.

Manabe, S. and Strickler, R. F.: Thermal equilibrium of the atmosphere with a convective adjustment, J. Atmos. Sci., 21, 361385, 1964.

Marquardt, C., Beyerle, G., Healy, S. B., Schmidt, T., Wickert, J., Neumayer, H., König, R., and Reigber, Ch.: Variational Retrieval of Champ Radio Occultation Data, European Geophysical Society XXVII General Assembly, Nice, 21-26 April, abstract N6004, 2002.

Medeiros, B., Hall, A., and Stevens, B.: What Controls the Mean Depth of the PBL?, J. Climate, 18, 3157-3172, 2005.

Mastepanov, M., Sigsgaard, C., Dlugokencky, E. Houweling, S., Strom, L., Tamstorf, M. P., and Christensen, T. R.: Large tundra methane burst during onset of freezing, Nature, 456, 628-630, 2008.

Mauritsen, T., Svensson, G., Zilitinkevich, S. S., Esau, I., Enger, L., and Grisogono, B.: A total turbulent energy closure model for neutral and stably stratified atmospheric boundary layers, J. Atmos. Sci., 64(11), 4117-4130, 2007.

North, G. R., Cahalan, R. F., and Coakley Jr., J. A.: Energy balance climate models, Rev. Geophys. Space Phys., 19(1), 91-121, 1981.

Ramanathan, V. and Coakley Jr., J. A.: Climate modelling through radiative-convective models, Rev. Geophys. Space Phys., 16, 465-489, 1978

Randall, D. A., Xu, K.-M., Somerville, R. J. C., and Iacobellis, S.: Single column models and cloud ensemble models as links between observations and climate models, J. Climate, 9, 16831697, 1996.

Serafin, S. and Zardi, D.: Critical evaluation and proposed refinement of the Troen and Marht (1986) boundary layer model, ICAM/MAP conference, 2005.
Steeneveld, G. J., Mauritsen, T., de Bruijn, E. I. F., Vila-Guerau de Arellano, J., Svensson, G., and Holtslag, A. A. M.: Evaluation of limited area models for the representation of the diurnal cycle and contrasting nights in CASES99, J. Appl. Meteorol. Clim., 47, 869-887, 2008.

Stone, D. A. and Weaver, A. J.: Factors contributing to diurnal temperature range trends in twentieth and twenty-first century simulations of the CCCma coupled model, Clim. Dynam., 20(5), 435445, 2003.

Uppala, S. M., Kållberg, P. W., Simmons, A. J., et al.: The ERA40 re-analysis, Q. J. Roy. Meteor. Soc., 131(612), 2961-3012, doi:10.1256/qj.04.176, 2005.

Tjernström, M.: The Summer Arctic Boundary Layer during the Arctic Ocean Experiment 2001 (AOE-2001), Bound.-Lay. Meteorol., 117, 5-36, 2005.

Troen, I. and Mahrt, L.: A simple model of the atmospheric boundary layer; sensitivity to surface evaporation, Bound.-Lay. Meteorol., 37, 129-148, 1986.

Vose, R. S., Easterling, D. R., and Gleason, B.: Maximum and minimum temperature trends for the globe: An update through 2004, Geophys. Res. Lett., 32, L23822, doi:10.1029/2005GL024379, 2005.

Walter, K. M., Zimov, S. A., Chanton, J. P., Verbyla, D., and Chapin III, F. S.: Methane bubbling from Siberian thaw lakes as a positive feedback to climate warming, Nature, 443, 71-75, 2006.

Walter, K. M., Smith, L. C., and Chapin III, F. S.: Methane bubbling from northern lakes: present and future contributions to the global methane budget, Phil. Trans. R. Soc. A, 365, 1657-1676, 2007.

Walters, J. T., McNider, R. T., Shi, X., Norris, W. B., and Christy, J. R.: Positive surface temperature feedback in the stable nocturnal boundary layer, Geophys. Res. Lett., 34, L12709, doi:10.1029/2007GL029505, 2007.

Zaliapin, I. and Ghil, M.: Another look at climate sensitivity, arXiv:1003.0253v1, 2010.

Zilitinkevich, S., Esau, I., and Baklanov, A.: Further comments on the equilibrium height of neutral and stable planetary boundary layers, Q. J. Roy. Meteor. Soc., 133, 265-271, 2007.

Zilitinkevich, S. S. and Esau, I.: Planetary boundary layer feedbacks in climate system and triggering global warming in the night, in winter and at high latitudes, Geography, Environment and Sustainability, 1(2), 20-34, 2009. 